\title{
Omamori: Harmonization of Humans and Their Environment in Cultural Symbols
}

\author{
Yuliani Rahmah* \\ Faculty of Humanities, Diponegoro University.
}

\begin{abstract}
Omamori is known as an important part of religious life in Japanese society. Omamori, which has been known since the Tokugawa era and still survives in modern Japanese society, is often known as part of the collective culture of Japanese society. However, behind its function as a spiritual medium, Omamori holds a meaning of harmony between humans and nature. With the library research, this article aims to explain the other meanings contained in an Omamori. It is in line with the teachings of Shinto whose concept is centered on nature and the environment. The form, type, and function of an Omamori also symbolize the meaning of harmony between humans and their environment that gives birth to attitudes that support the preservation of the natural environment.
\end{abstract}

\section{Introduction}

The preservation of nature and the environment is one of the positive attitudes of Japanese people that must be emulated by the nations and the world. Their concern for nature and its preservation is not stopped by modernization and technological advancements that they develop. Amid modern society that lives fast and instant, they do not hesitate to conduct discipline related to environmental preservation. There are many examples of their behavior that supports nature preservation, one of them is by sorting waste to create environmentally friendly objects. Their behavior did not come by itself but has become a life commitment based on collective knowledge that has been hereditary, one of which is the ideology they believe in.

As we all know, most Japanese people adhere to the Shinto religion which is believed to be the original religion of Japanese society. It is uncertain who first taught Shinto beliefs, and initially, it did not even have names, dogmas, or even scriptures. From mythology known as Kiki mythology, it is known that the stories conveyed by Shinto teachings are related to the origin of the universe, the occurrence of land, the birth of the gods and goddesses, and also the emperor's family $[1,2]$.

Shinto as a popular belief believes that the entire universe is the abode of "kami gami" or the gods. Kami gami is not limited to just staying in a certain place, but can also dwell on an object. That is why followers of Shinto religion must preserve and respect the universe. This form of obligation is known as Shizenkan (自然 感) [3].

\footnotetext{
${ }^{*}$ Corresponding author : yuliani.rahmah@live.undip.ac.id
} 
In Shinto teachings, the belief in the harmonization of the kami power becomes crucial. The existence of kami is in every natural object, such as mountains, forests, waterfalls, winds, and so on. With the existence of kami in the natural object, it is believed that kami will be able to guide the straight path so that everyone can live according to the path of truth [2].

When viewed from the Shinto teachings that have been strongly embedded in the lives of Japanese society, it can be understood how their attitudes in protecting their surrounding natural environment which is closely related to something scared. This becomes interesting considering that attitude still survives in modern times like today. Harmonization that they do is not only seen from everyday attitudes but even to the small things related to their beliefs. Also, one of them is a small object that is believed to be a protective object called Omamori. This then becomes the basis of the writer's interest to study more deeply about what kind of harmonization can be shown by a small object that is part of the Japanese culture.

\section{Discussion}

The close relationship between humans and nature is inseparable. The belief that nature itself is a part that consists of positive and negative energy that can cause good and bad nature (evil), makes them believe that they must ask for the protection of the gods so that they can still live in the truth that well synergizes with nature. Therefore, Omamori is one of the protection media used as a "talisman" guard by Japanese society until now [4].

To be able to see what kind of harmonization portrayed in an Omamori, it will first be presented with a general description of one of the symbols of the Japanese culture.

\subsection{Omamori in Japanese Culture}

Most Japanese people believe that Omamori is an object that can be used as a medium of protection from bad luck. The Omamori is generally in the form of a bag made of decorated fabric and inside, it has paper folds or pieces of a wood bearing the name of the god. The paper folds have been prayed for to provide protection and luck to the owner. Japanese people believe that Omamori is a sacred object that holds the power of the gods. Therefore, according to their belief, if the wrapper is opened, then the talisman will lose its protective power.

Omamori, also known as Mamorifuda, is usually sold in Shinto shrines (otera) and Buddha temples (otera) and is available in various names to bring safety and good fortune in various places and situations. It is stated that there are differences in Omamori between two temples where according to the belief of Japanese people, Omamori from Buddhist temples contains many prayers while Omamori from Shinto shrines is inhabited by the spirits of the gods [5].

\subsection{Types of Omamori}

Prayers and requests for protection that are often requested by the Japanese society in the Omamori are commonly cover the entire life cycle of a human being from before birth until the human dies. This makes each cycle requires a different protection media. For example, in the first cycle of a human's early stage of life or when the human still insides the mother's womb, Japanese society will pray and request kami (gods) who maintain health and smooth birth through anzan-mamori (安産). Then, when someone starts entering the world of education, the Japanese society will hang their hopes and prayers of the power of 
the gods contained in gakugyoujoju-mamori (学業成就). When someone starts to enter the business world, they use shoubai hanjo-mamori (商売繫盛) to get the gods to help them run their business smoothly. When a person's life cycle arrives at the phase of searching for a life partner, then there is an enmusubi-mamori (縁結び) which is believed to help the owner find a marriage partner through kami's guidance and strength in the Omamori. In addition to prayer and protection for every phase of life, there are also Omamori that is believed to protect them from negative influences such as Yaku yokemamori (厄除) that is believed to protect them from demonic or occult interference or kotsuu anzen- mamori (交通安全) that is believed to protect the owner when traveling [2].

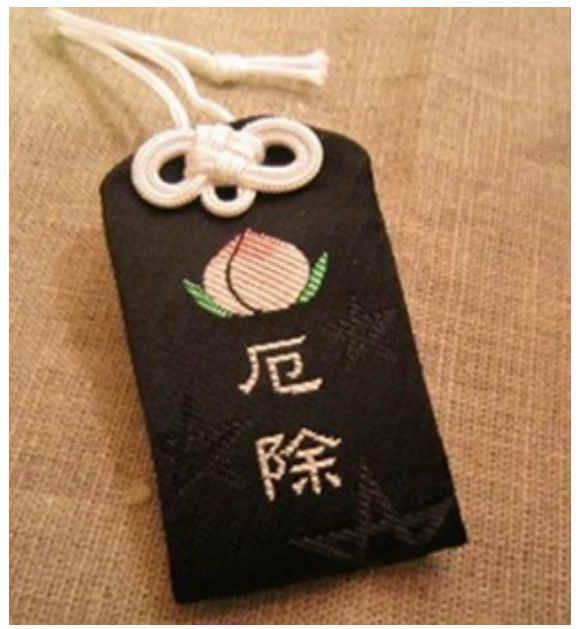

Picture 1. Yaku yoke mamori [6]

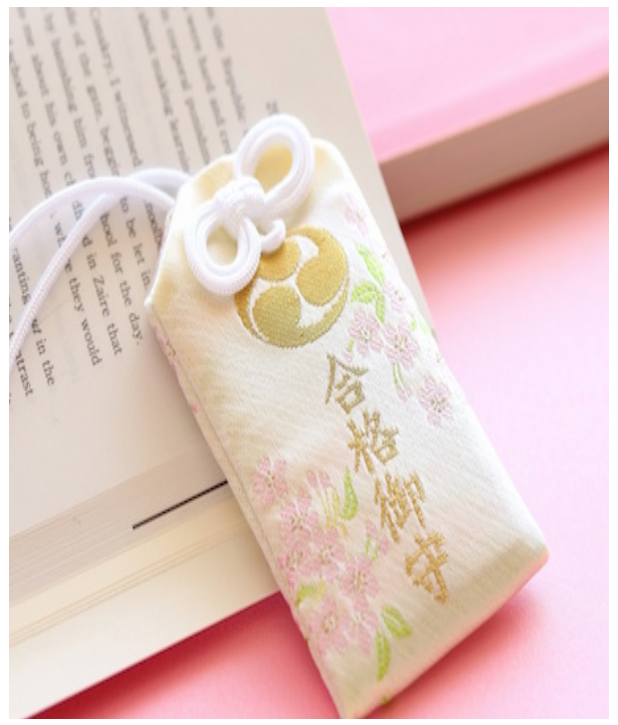

Picture 3. Gakugyoujoju mamori [6]

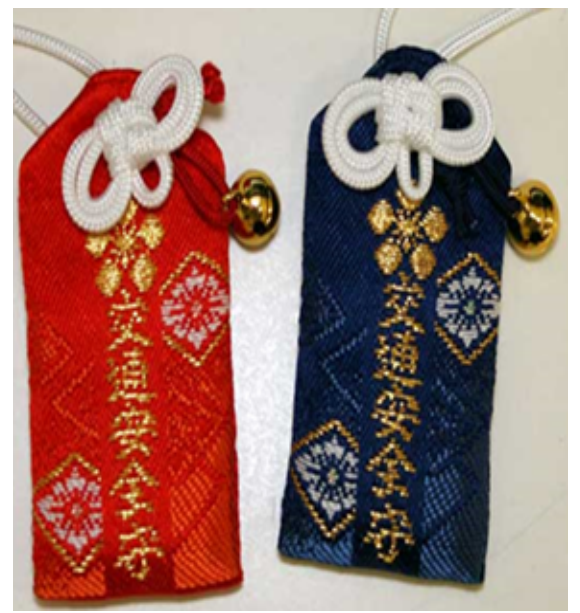

Picture 2 Kotsuu anzen mamori [7]

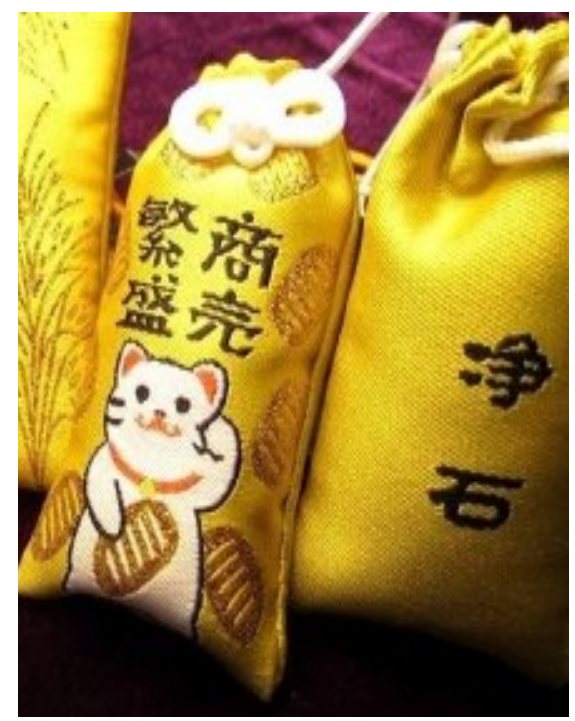

Picture 4. Shobai hanjou mamori [6] 


\subsection{Omamori as a symbol of harmony between humans and the environment}

As explained earlier, Omamori is the result of Shinto that emphasizes its teachings on human attachment to the natural surroundings. This influence can be seen even in the tools and equipment used in the worship process, one of which is the Omamori that is part of their belief in the power of gods. Like other objects, Omamori was created by incorporating natural elements that are quite dense. The first thing that can be seen is the use of the material of the Omamori itself. The Shinto teachings, which have a high degree of existence and harmony with nature, are manifested in the form of an Omamori. The Omamori is commonly shaped in the form of a bag made of decorated fabric in which there are folds of paper of pieces of wood bearing the name of the god inside [2].

The use of pieces of wood and paper is a reflection of respect for nature and the existence of gods. Then, when looking closely at the wrapping cloth, it can be seen that the decoration on the Omamori wrapper is always associated with objects that exist in surrounding nature, such as floral motifs, fruits, leaves, or other plants that show fertility and serenity. Other motifs that are also often found in Omamori are the shape of the moon, stars, or fraction of light.

The belief of the Shinto that kami gami resides in anywhere and any form, make Omamori believed to be a form of strength of kami who live in the piece of the wood, so humans will always remember to keep it from damage. The use of Omamori material teaches humans that no matter how small we take from nature and be taken care of: nature will reciprocate by giving protection to humans.

Furthermore, Omamori, which is part of the concept of Shinto belief that believed that each god has different strengths, makes Japanese people believe that all forms that spread in the natural environment are something that must be maintained properly. Each type is believed to be a place where certain deities reside which helps to realize their desires. Also, with the belief that gods can also be present in animal figures, it raises the obligation to always be compassionate towards all animals that live alongside nature. This was the reason there are foxes, cats, and dogs Omamori. Moreover, the belief that every human being is given life by gods and their life is sacred, has become the basis of the belief that humans are good beings where evil committed by humans is caused by evil spirits. With this belief, to avoid the interference of evil spirits, humans need Omamori as a medium of the power of the gods to prevent the evil spirits from affecting humans. By having Omamori, the power of kami/gods contained in it will be able to guide humans on a straight path so that those who live their lives according to the kamis's instructions are protected.

\section{Conclusions}

The existence of Omamori as part of Japanese culture is a manifestation of the beliefs of Japanese people that are very well united with nature. The understanding, that is based on the belief in the existence of the gods in the natural surroundings where humans live, has given birth to a principle that humans live alongside with the natural environment in harmony. The love of nature and environment which then becomes part of daily life is not only manifested in the attitudes and daily activities of nature conversation, balanced environmental preservation, and nurturing nature and everything in it, but also reflected in the cultural objects they produce as a collective culture.

The symbol of harmony between humans and the natural environment that is manifested in an Omamori is not only visible from the materials and motifs that characterize the Omamori, but can also be seen from the type and function of the Omamori itself which indirectly provides environmental education in each phase of the lives of the adherents to always maintain the natural environment as part of their belief in the protection of the gods. 


\section{References}

[1] Herlina,Sandra. Al-Azhar Indonesia Journal,Humaniora.Series. 1 ; 2(2011)

[2] Rahmah,Yuliani. Kiryoku Journal .3,2 (2019)

[3] Pratiwi, Citra Ayu. Japanology Journal 5;2 (2017)

[4] http://mittsu-sekai.blogspot.com/2012/05/ofuda.html

[5] https://matcha-jp.com/id/1001

[6] japanesestation.com

[7] matome.naver.jp

[8] Fatonah, Komunikasi Global Journal. 7,1 (2018)

[9] Handayani, Ratna. Lingua Cultura Journal. 3,1(2009)

[10] Mulyadi, Budi. Izumi Journal 1;1(2017)

[11] Sholikhah Sitti Rahmatus, Saraswati Tia .Japanology Journal. 5;1 (2016). 